Sādhanā Vol. 37, Part 1, February 2012, pp. 89-105. (C) Indian Academy of Sciences

\title{
Evaluation of size effect on shear strength of reinforced concrete deep beams using refined strut-and-tie model
}

\author{
G APPA RAO* and R SUNDARESAN \\ Indian Institute of Technology, Madras, India, Chennai 600 036, India \\ e-mail: garao@iitm.ac.in
}

\begin{abstract}
This paper reports on development of size-dependent shear strength expression for reinforced concrete deep beams using refined strut-and-tie model. The generic form of the size effect law has been retained considering the merits of Siao's model and modified Bazant's size effect law using the large experimental data base reported in the literature. The proposed equation for predicting the shear strength of deep beams incorporates the compressive strength of concrete, ratios of the longitudinal and the web reinforcement, shear span-to-depth ratio and the effective depth.
\end{abstract}

Keywords. Deep beams; strut-and-tie models; reinforced concrete; size effect; shear span-to-depth ratio.

\section{Introduction}

\subsection{Size effect in ordinary beams}

The shear strength of reinforced concrete beams which decreases with increase in depth is prominently described as the size effect. The evidence of the size effect has been emphasized through several research efforts made on normal beams $(a / d \geq 2.5)$. Some predictive equations have been proposed for evaluating the size-dependent shear strength of such beams. Walsh (1972) confirmed that the critical strength of the concrete beams decreases with increase in the beam depth, where a characteristic depth of $225 \mathrm{~mm}$ has been identified to observe the size effect on concrete beams. Bazant $(1980,1983)$ was responsible for developing size effect law based on infinite series and limiting its applicability to the size range of 1:32.

\subsection{Size effect in deep beams}

An extensive experimental investigation on various sizes of beams without shear reinforcement with different shear span to-depth ratios, Kani (1967) confirmed the existence of strong size effect on the ultimate shear strength of RC beams. About $40 \%$ of the strength reduction was observed when the beam depth was increased from $300 \mathrm{~mm}$ to $1200 \mathrm{~mm}$. Later, several

*For correspondence 
studies have been made to understand the behaviour of deep beams without web reinforcement (Shioya et al 1989), in which further $25 \%$ reduction of shear strength was observed when the beam depth increased from $1200 \mathrm{~mm}$ to $3000 \mathrm{~mm}$. Though, the size effect has been observed in deep beams with web reinforcement according to the scarcely reported experimental data, there is lack of simple prediction.

\subsection{Need for size-dependent strength}

The aim of the proposal of size-dependent models for evaluation of the shear strength of reinforced concrete structures is not only to predict the reduction of strength with increase in beam size, but also to ensure uniform margin of safety irrespective of the size. Further, the ductility of $\mathrm{RC}$ beams in shear significantly decreases with increase in size. Since high-strength concrete is brittle in nature as compared to the conventional strength concrete, use of fracture mechanics of concrete is inevitable to obtain the strength and ductility-based on size effect.

\subsection{Aspects of size effect}

Among the two forms of size effect namely; statistical and deterministic, the statistical size effect law is based on the randomness of the material strength. This type of size effect affects the strength only prior to the peak stress. But, the concrete on the other hand, possesses ample reserve strength after the peak stress. The deterministic one is the dominant size effect often observed after the peak stress and is caused by the release of the stored elastic energy through crack tip and crack propagation.

\section{Research significance}

Reliable analytical models for predicting the shear strength of deep beams are lacking. A simple equation for predicting the shear strength of reinforced concrete deep beams $(a / d \leq 1)$ with web reinforcement is proposed using refined strut-and-tie model, generic form of the size effect law existing from the available experimental data. Prediction of the shear strength based on the proposed model agrees well with the experimental data base.

\section{Failure mechanism}

The failure mechanism in deep beams, with $a / d \leq 1$, differs significantly from that of the slender beams due to formation of struts and ties that enhance the shear resistance. Since the failure phenomenon is different in deep beams, the available size effect law for slender beams cannot be applicable for deep beams.

\section{Strut-and-tie model}

In strut-and-tie models, the compressive forces are assumed to be carried by a portion of the concrete between diagonal cracks known as struts, and the tensile forces are considered to 
be borne by the tension steel reinforcement called ties. The strut-and-tie models are mainly applied to special regions of beams such as geometrical discontinuities, load points, deep beams, corbels and pile caps, where the classical beam theory does not yield the appropriate results. The applicability of these models to structural components was attempted by Schlaich et al (1987) by considering uniformly formed concrete struts between inclined cracks over the entire length of the beam.

\section{Size effect laws}

\subsection{Bazant's size effect law}

Based on the dimensional analysis of the strain energy release rate, Bazant (1984) proved that the failure stress varies as $\left(1+d /\left(d_{a} \lambda_{0}\right)\right)^{-1 / 2}$, in which $d=$ beam depth, $d_{a}=$ maximum size of coarse aggregate, and $\lambda_{0}=$ constant. This indicates that the nominal stress decreases with increasing beam size.

\subsection{Modified Bazant's size effect law}

Despite good agreement of the size effect law proposed by Bazant with the test results, there exists some discrepancy as reported by Kim \& Park (1996) between the prediction by Bazant's law and the test data, particularly for large-size specimens. To minimize this discrepancy, the authors of this paper developed a modified size effect law, without disturbing the generic form, using (Kim \& Eo 1990) law based on the concept of dissimilar initial cracks as given by

$$
\sigma_{N}=\frac{k_{1} \sigma_{r}}{\left(1+k_{4} d\right)^{1 / 2}}+k_{2} \sigma_{r}
$$

where $\sigma_{N}$ is the nominal strength of beam at failure, $\sigma_{r}$ is the size independent nominal strength of the beam, $k_{1}, k_{2}$, and $k_{4}$ are empirical constants. For the purpose of dimensional balancing and to maintain the generic form of Bazant's size effect law, the modified Bazant's law (Eq. 1) can be written as

$$
\begin{aligned}
\sigma_{N} & =\frac{k_{1} \sigma_{r}}{\left(1+d /\left(d_{a} \lambda_{0}\right)\right)^{1 / 2}}+k_{2} \sigma_{r} \\
& =k_{1} \sigma_{r}\left(\frac{k_{2}}{k_{1}}+\frac{1}{\left(1+\left(1 / \lambda_{0}\right)\left(d / d_{a}\right)\right)^{1 / 2}}\right) .
\end{aligned}
$$

\subsection{Refined strut-and-tie model for deep beams}

The internal forces in the refined strut-and-tie in a deep beam on the application of external forces are shown in figure 1 . The tensile stress in concrete, $f_{t}$ acting normal to diagonal $\mathrm{AB}$ is obtained as per Siao's model (1993) using refined strut-and-tie model as

$$
f_{t}=\frac{V}{2 \sin \alpha}\left(\frac{\sin \alpha}{b z}\right)=\frac{V}{2 b z},
$$




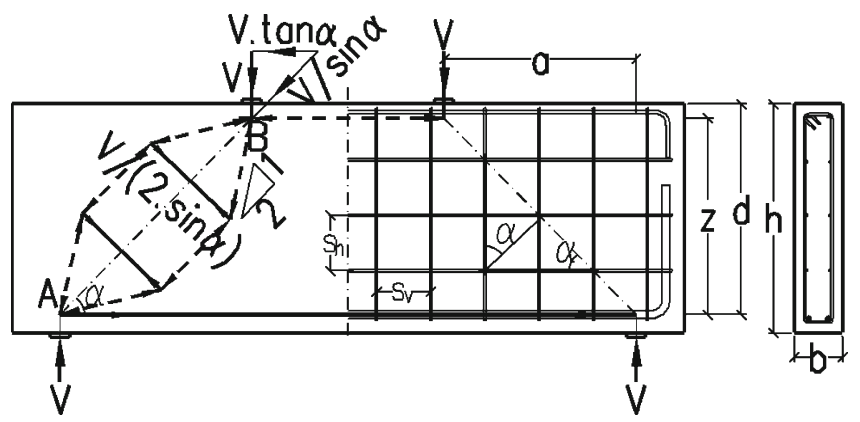

Figure 1. Refined strut-and-tie model for RC deep beam.

where $V$ is the shear force at the beam section, $b$ is the breadth of the beam, and $z$ is the lever arm between centroids of main steel reinforcement near the bottom of the beam and the compression strut near the top of the beam.

\subsection{Effect of steel ratio on lever arm}

The lever arm, $z$ in Eq. (3) can be expressed as $z=j_{0} d$ in which $j_{0}$ is a constant, defining the location of the resultant of the compression force at the end of the shear span, $a$. According to the classical bending theory of RC beams with only tensile reinforcement and with negligible tensile strength of concrete, the neutral axis depth and the lever arm coefficients can be expressed as below

$$
j_{0}=1-\frac{k}{3}, \quad k=\sqrt{(n \rho)^{2}+2 n \rho}-n \rho,
$$

where $k$ is the ratio of the depth of the neutral axis (c)-to-the effective depth (d), $n$ is the modular ratio of tensile reinforcement to concrete and $\rho$ is the main reinforcement ratio. The value of $j_{0}$ may be expressed in a simpler form as $j_{0}=C_{1} / \rho^{b 1}$.

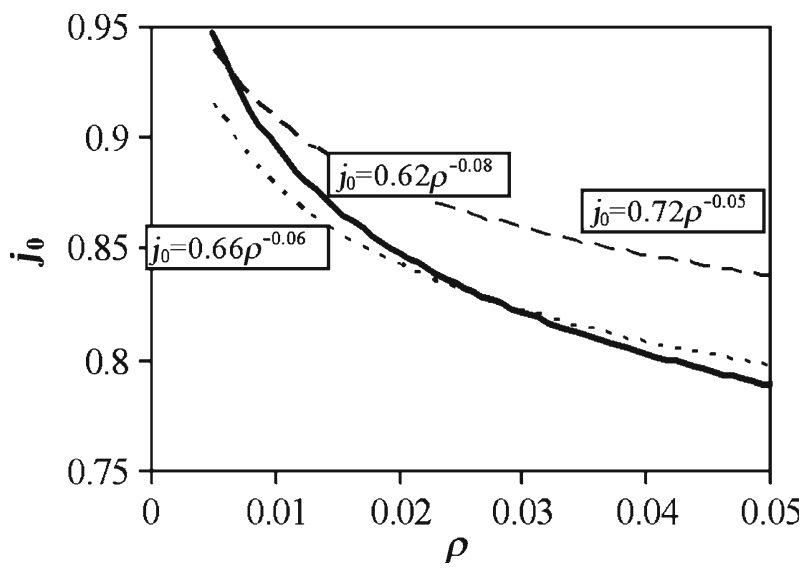

Figure 2. Relation between $j_{0}$ and $\rho$. 
In practice, the modular ratio, $n$ varies between 5.0 and 10.0, and that of the main reinforcement ratio, $\rho$ between 0.005 and 0.05 . For the above ranges of $n$ and $\rho$, we can obtain the power function for $j_{0}$ as $0.62 \rho^{-0.08}$ based on the similar equation proposed by Kim et al (1999). Figure 2 shows the plot of the function covering the above practical range of values for $n$ and $\rho$. For the RC deep beams with short shear span, the linear elastic theory provides better estimate of $j_{0}$ because the inclined shear cracks initiate when the load on the beam is far below the full flexural capacity.

\subsection{Shear strength of concrete}

The tensile strength of concrete, $f_{c t}$ is assumed as a function of square root of compressive strength of concrete.

$$
f_{c t}=0.5 \sqrt{f_{c}^{\prime}}
$$

Across the diagonal, $\mathrm{AB}$ as shown in figure 1, substituting the value of $f_{c t}$ for $f_{t}$ in Eq. (3) and expressing the lever arm, $z$ in terms of the effective depth as $z=j_{0} d$, we can obtain the shear strength of concrete, $v_{c}$ as

$$
v_{c}=\frac{V}{b d}=j_{0} \sqrt{f_{c}^{\prime}}
$$

\subsection{Effect of inclination of strut}

The flexural cracks in concrete in tension can penetrate into the diagonal strut at higher $a / d$ ratios. In other words, if the diagonal strut is flatter the possibility of penetration of flexural cracks into the diagonal struts is high. Such flexural cracks can cause reduction in the carrying capacity of the concrete struts. At small $a / d$ ratios, the flexural cracks cannot penetrate into the diagonal strut. In view of this behaviour, the strength of RC deep beams can be considered to be inversely proportional to the $a / d$ ratio.

\subsection{Effect of longitudinal reinforcement}

The longitudinal tensile reinforcement can resist a portion of the shear force immediately after the formation of the diagonal cracks. The dowel action of the longitudinal reinforcement is responsible for increase in the shear strength with increase in the percentage of longitudinal reinforcement. It is well-known that the shear strength of RC beams is proportional to the amount of the longitudinal reinforcement.

\subsection{Size independent strength of concrete}

In order to account for the effect of a/d ratio and the longitudinal reinforcement ratio, the shear strength of concrete, $v_{c}$ in Eq. (5) can now be modified as below

$$
v_{c}=\frac{A_{1}(\rho)^{a 1} j_{0} \sqrt{f_{c}^{\prime}}}{1+B_{1}(a / d)} .
$$


In the above form, the shear strength is independent of the size of the beam. Hence, the shear strength is called size independent strength of concrete.

\subsection{Size-dependent strength of concrete}

In order to account for the effect of beam size on shear strength of concrete, the term $v_{c}$ in Eq. (6) is substituted for $\sigma_{r}$ in Eq. (2). Now, the size-dependent stress is rearranged by replacing the lever arm distance, $j_{0}=0.62 \rho^{-0.08}$

$$
v_{c}=\frac{A_{1} k_{1} 0.62(\rho)^{a 1-0.08} \sqrt{f_{c}^{\prime}}}{1+B_{1}(a / d)}\left(\frac{k_{2}}{k_{1}}+\frac{1}{\left(1+\left(1 / \lambda_{0}\right)\left(d / d_{a}\right)\right)^{1 / 2}}\right) .
$$

Replacing the constants $\left(A_{1} k_{1} 0.62\right)$ and $\left(a_{1}-0.08\right)$ with $D_{1}$ and $d_{1}$ respectively, we can rewrite the above expression as

$$
v_{c}=\frac{D_{1}(\rho)^{d 1} \sqrt{f_{c}^{\prime}}}{1+B_{1}(a / d)}\left(\frac{k_{2}}{k_{1}}+\frac{1}{\left(1+\left(1 / \lambda_{0}\right)\left(d / d_{a}\right)\right)^{1 / 2}}\right) .
$$

\subsection{Effect of horizontal web reinforcement}

If $A_{h}$ is the area of the horizontal web (shear) reinforcement provided in each layer at a vertical spacing, $s_{h}$, the shear strength contributed by the horizontal web reinforcement shall be calculated as

$$
\begin{aligned}
v_{s t h} & =\left(\frac{d}{s_{h}} A_{h} f_{y} \tan \alpha\right) \frac{1}{b d} \\
& =\frac{A_{h}}{b s_{h}} f_{y} \frac{0.62 \rho^{-0.08} d}{a} .
\end{aligned}
$$

In RC deep beams, the tension reinforcement is not subjected to its full yield stress. To account for the stress in steel reinforcement, the equation is magnified with a constant $E_{1}$, which is shown below

$$
v_{s t h}=E_{1} 0.62 \rho^{-0.08} \rho_{h} f_{y} \frac{d}{a} .
$$

In the above expression, replacing the product $\left(E_{1} 0.62\right)$ by another constant $F_{1}$ and rewriting the equation, the following form is obtained

$$
v_{s t h}=F_{1} \rho^{-0.08} \rho_{h} f_{y} \frac{d}{a} .
$$

\subsection{Effect of vertical web reinforcement}

Similarly, if $A_{v}$ is the area of the vertical web reinforcement provided at a horizontal spacing, $s_{v}$, the shear strength offered by the vertical web reinforcement can be expressed in the following expression

$$
\begin{aligned}
v_{s t v} & =\left(\frac{a}{s_{v}} A_{v} f y\right) \frac{1}{b d} \\
& =\frac{A_{h}}{b s_{v}} f_{y} \frac{a}{d} .
\end{aligned}
$$


Multiplying the above equation with a constant $G_{1}$ to account for the effectiveness of the vertical web reinforcement, the shear strength expression can be written as

$$
v_{s t v}=G_{1} \rho_{v} f_{y} \frac{a}{d} \text {. }
$$

\subsection{Total nominal shear stress}

The total nominal shear strength, $v_{n}$ offered by the concrete and the web reinforcement shall be calculated by summing up the shear strength in Eqs. (7), (8) and (9).

$$
\begin{aligned}
v_{n} & =v_{c}+v_{s t h}+v_{s t v} \\
& =\frac{D_{1}(\rho)^{d 1} \sqrt{f_{c}^{\prime}}}{1+B_{1}(a / d)}\left(\frac{k_{2}}{k_{1}}+\frac{1}{\left(1+\left(1 / \lambda_{0}\right)\left(d / d_{a}\right)\right)^{1 / 2}}\right)+F_{1} \rho^{-0.08} \rho_{h} f_{y} \frac{d}{a}+G_{1} \rho_{v} f_{y} \frac{a}{d},
\end{aligned}
$$

in which the constants $B_{1}, D_{1}, d_{1} k_{1}, k_{2}, F_{1}, G_{1}$ and $\lambda_{0}$ are to be determined from the nonlinear regression analysis of the selected data base. For the evaluation of these coefficients, the experimental data consisting of 96 tests on deep beam reported (Smith \& Vantsiotis 1982; Kong et al 1970; de Paiva \& Siess 1965; Tan et al 1995, 2001; Tan \& Lu 1999; Oh \& Shin 2001; Quitero-Febres et al 2006) have been used. Using nonlinear optimization (Levenberg-Marquardt algorithm), and also from the trial and error approach the coefficients are obtained. Equation (10) can now be expressed after substituting the coefficients so obtained as

$$
v_{n}=\frac{11.40 \rho^{0.35} \sqrt{f_{c}^{\prime}}}{1+2(a / d)}\left(0.38+\frac{1}{\left.\sqrt{1+\left(d /\left(25 d_{a}\right)\right.}\right)}\right)+0.02 \rho^{-0.08} \rho_{h} f_{y}\left(\frac{d}{a}\right)+0.31 \rho_{v} f_{y}\left(\frac{a}{d}\right) .
$$

\section{Existing strut-and-tie and size effect models}

Different forms of the strut-and-tie models are effectively attempted for predicting the shear strength of reinforced concrete deep beams so far (Siao 1993; Matamoros \& Wong 2003; Tan et al 2003a, b; Tang \& Tan 2004; Russo et al 2005). ACI-08 (2008), Canadian Code (1994) and AASHTO (2007), also recommended use of the strut-and-tie models for the design of deep beams. Even though the above model predicts the size independent shear strength of deep beams, there are few size effect models by Tan \& Cheng (2006) and Zhang \& Tan (2007), which can evaluate the size-dependent shear strength of deep beams. These size effect equations are discussed below.

\subsection{Tan and Cheng's model}

$$
V_{n}=\frac{1}{\frac{\sin 2 \theta_{s}}{f_{t} A_{c}}+\frac{1}{v f_{c}^{\prime} A_{s t r} \sin \theta_{s}}}
$$




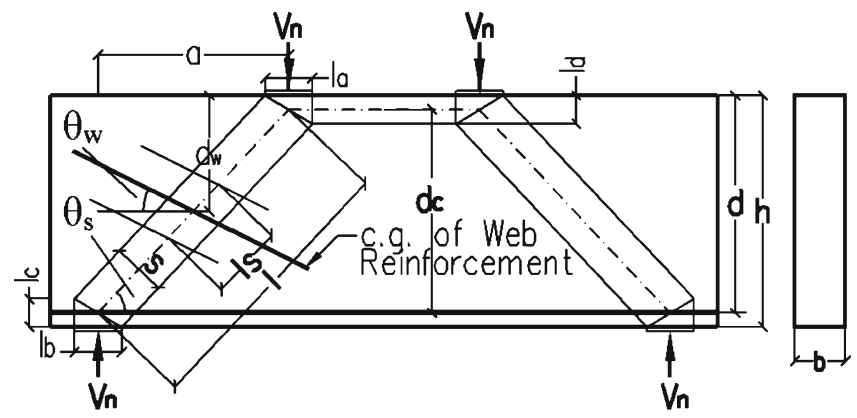

Figure 3. Tan and Cheng's model for simply supported deep beams.

where $\theta_{s}=$ inclination of the diagonal strut (figure 3 ), $A_{c}=$ area of cross-section of the beam, $A_{\text {str }}=$ cross-sectional area of the strut, $f_{c}^{\prime}=$ cylindrical compressive strength of concrete and

$$
\begin{aligned}
v & =\xi \zeta ; \xi=0.8+\frac{0.4}{\sqrt{1+(l-s) / 50}} \\
\zeta & =0.5+\sqrt{\frac{k d_{s}}{l_{s}}} \leq 1.2 ; k=\frac{\sqrt{\pi}}{2} \sqrt{\frac{f_{y}}{0.5 \sqrt{f_{c}^{\prime}}}} \\
f_{t} & =\frac{2 A_{s} f_{y} \sin \theta_{s}}{A_{c} / \sin \theta_{s}}+\sum \frac{2 A_{w} f_{y w} \sin \left(\theta_{s}+\theta_{w}\right)}{A_{c} / \sin \theta_{s}} \frac{d w}{d}+0.5 \sqrt{f_{c}^{\prime}},
\end{aligned}
$$

in which $A_{s}$ and $A_{w}$ are areas of longitudinal and web reinforcement respectively, $f_{y}$ and $f_{y w}$ are respectively the yield strength of the longitudinal and the web reinforcement, $\theta_{w}$ is the inclined angle of the intercepted web reinforcement with the horizontal, $d_{s}$ is the diameter

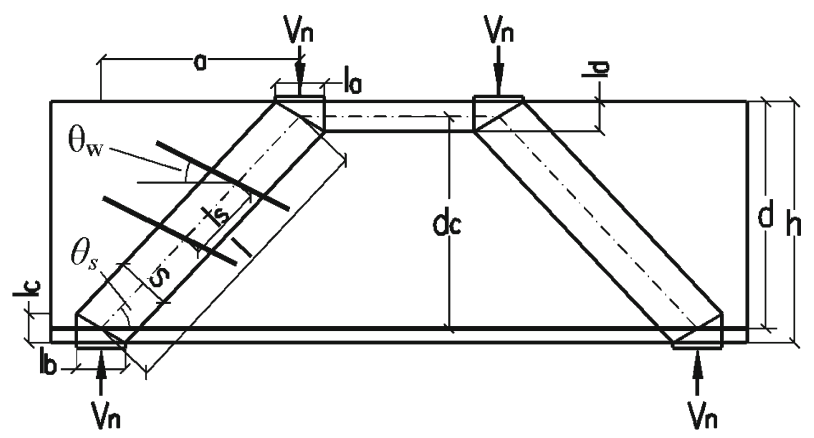

Figure 4. Zhang and Tan's model for simply supported deep beams. 
of the web reinforcement bar when the web reinforcement is not provided, $d_{s}$ is the minimum diameter of the bottom longitudinal reinforcement bars and $d_{w}$ is taken from the top of the beam to the intersection of the web reinforcement with the centreline of the inclined strut (figure 3).

\subsection{Zhang and Tan's model}

Zhang and Tan's model (2007) for estimating the shear strength of deep beams is as follows

$$
V_{n}=\frac{1}{\frac{2 \sin 2 \theta_{s}}{f_{t} A_{c}}+\frac{\sin \theta_{s}}{v f_{c}^{\prime} A_{s t r}}},
$$

where $\theta_{s}$ is the angle of inclination of the diagonal strut as shown in figure $4 ; f_{c}^{\prime}$ is the cylindrical compressive strength of concrete; $A_{c}$ is the cross-sectional area of the deep beam; $A_{s t r}$ is the
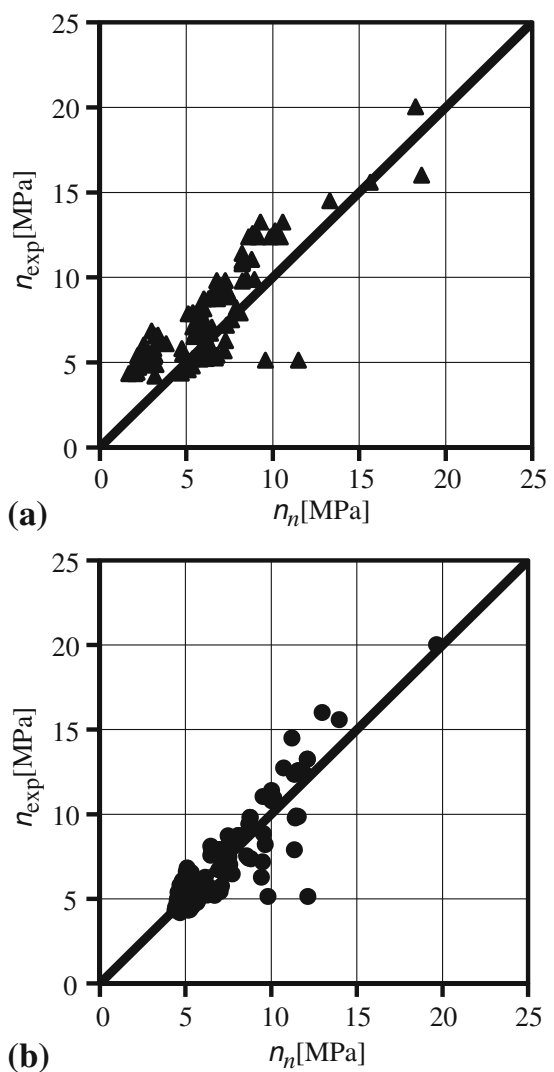

Figure 5. Nominal shear strength obtained from (a) Zhang and Tan's model; and (b) proposed equation versus experimentally observed values for 96 reinforced concrete deep beams. 
cross-sectional area of the diagonal strut and $f_{t}$ is the maximum tensile strength of the bottom nodal zone calculated as

$$
f_{t}=\frac{4 A_{s} f_{y} \sin \theta_{s}}{A_{c} / \sin \theta_{s}}+\sum \frac{f_{y w} A_{s w} \sin \left(\theta_{s}+\theta_{w}\right)}{A_{c} / \sin \theta_{s}}+0.31 \sqrt{f_{c}^{\prime}}\left(\frac{\varepsilon_{c r}}{\varepsilon_{1}}\right)^{0.40},
$$

where $A_{s}$ and $A_{s w}$ are the total areas of the longitudinal and the web reinforcement, respectively; $f_{y}$ and $f_{y w}$ are the yield strengths of the longitudinal and web reinforcement respectively; $\theta_{w}$ is the inclined angle of the web reinforcement with the horizontal (figure 4); $\varepsilon_{c r}$ is the strain in concrete at cracking $=0.00008 ; \varepsilon_{1}$ is the principal tensile strain in the concrete strut calculated from $\varepsilon_{1}=\varepsilon_{s}+\left(\varepsilon_{s}+\varepsilon_{2}\right) \cot ^{2} \theta_{s}$, where $\varepsilon_{s}$ and $\varepsilon_{2}$ are the tensile strain in the longitudinal reinforcement, and peak compressive strain in concrete strut at crushing respectively. The value of $\varepsilon_{2}$ is taken as 0.002 for normal strength concrete. The term $v$ is the efficiency factor, which is taken as the product of $\xi$ and $\zeta$, where $\xi$ accounts for the geometry of the strut
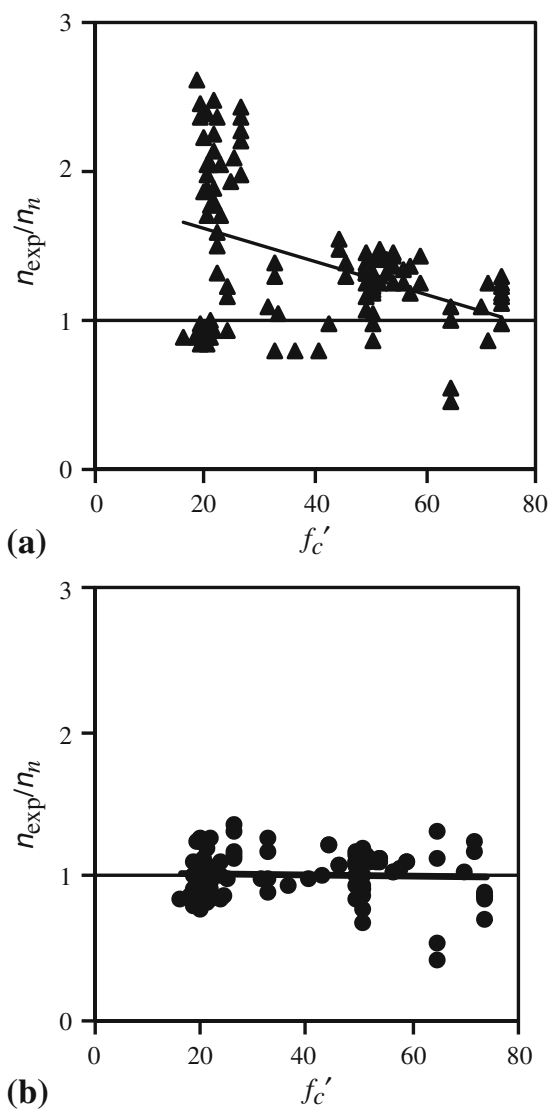

Figure 6. Effect of concrete strength $f_{c}^{\prime}$ on shear strength: (a) Zhang and Tan's model; and (b) proposed expression for 96 reinforced concrete deep beams. 
and $\zeta$ for the boundary condition influenced by the web reinforcement. These parameters are expressed as

$$
\begin{aligned}
& \xi=0.8+\frac{0.4}{\sqrt{1+(l-s) / 50}} \\
& \zeta=0.5+\sqrt{\frac{k d_{s}}{l_{s}}} \leq 1.2,
\end{aligned}
$$

where $l$ and $s$ are the length and the width of the strut, respectively (figure 4). The term $d_{s}$ is the diameter of the web reinforcement. When the web reinforcement is not provided, $d_{s}$ is taken as the minimum diameter of the bottom longitudinal reinforcing bars and the material factor
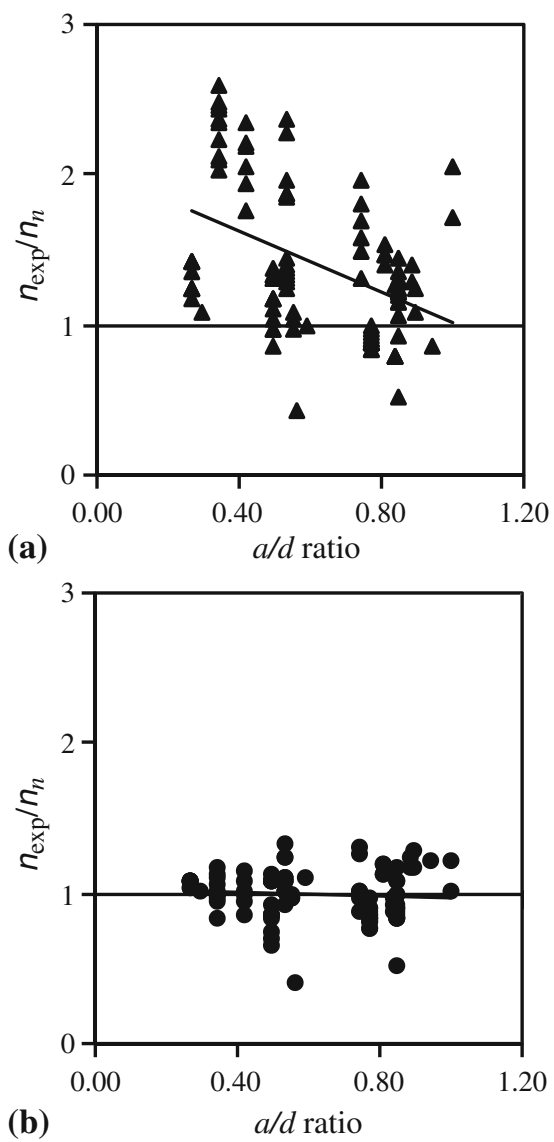

Figure 7. Effect of $a / d$ ratio on shear strength: (a) Zhang and Tan's model; and (b) proposed expression for 96 reinforced concrete deep beams. 
incorporating the yield strength of the reinforcing bar, $f_{y}$ and the tensile strength of concrete, $f_{c t}$ is given as

$$
k=\frac{1}{2} \sqrt{\frac{\pi f_{y}}{f_{c t}}},
$$

when the web reinforcement is not provided, it is taken as the half of the above value. The term, $l_{s}$ is the maximum spacing of the web reinforcement intercepted by the inclined strut.

\section{Verification of the model}

\subsection{Predicted nominal shear stress vs. experimental shear stress at failure}

The nominal shear strength, $v_{n}$ of the deep beams has been evaluated by the proposed equation and also by the iterative procedure adopted by Zhang \& Tan (2007). The calculated nominal shear strength, $v_{n}$ versus the experimental shear strength, $v_{\text {exp }}$ are plotted for both the models in
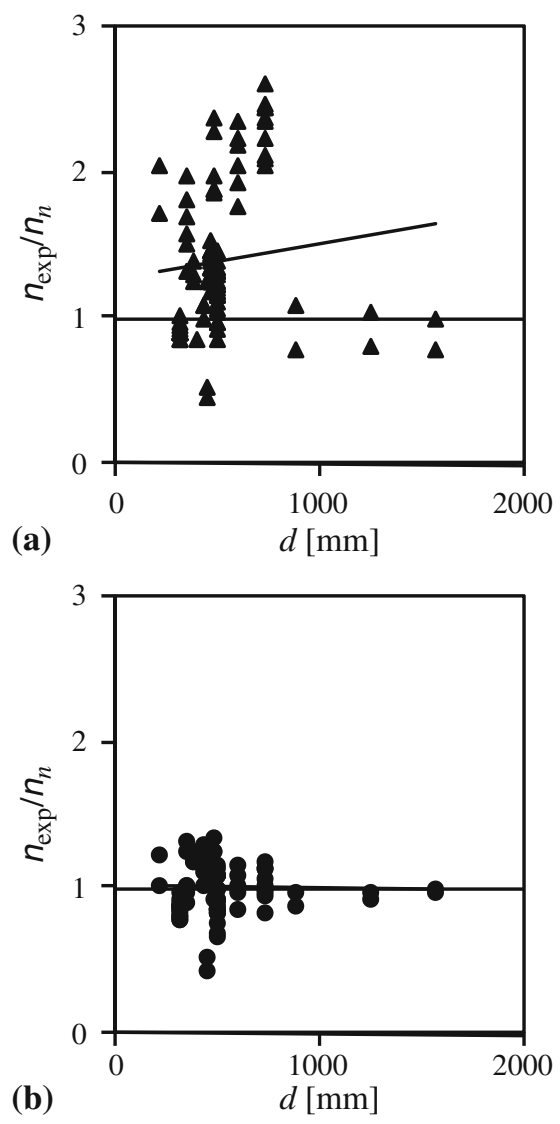

Figure 8. Effect of effective depth, $d$ on shear strength: (a) Zhang and Tan's model; and (b) proposed expression for 96 reinforced concrete deep beams. 
figure 5. The coefficient of variation (COV) of the proposed equation is 0.16 which is $55 \%$ less than the coefficient of variation obtained from Zhang and Tan's model.

\subsection{Shear stress ratio vs. strength of concrete}

The ratio of the experimental shear stress at failure to the predicted nominal stress has been plotted against the strength of concrete in figure 6. Zhang and Tan's model tend to overpredict the shear strength as the strength of concrete increases as compared to the proposed equation.

\subsection{Shear stress ratio vs. shear span-to-depth ratio}

Since the effect of cracking is accounted through shear span-to-depth ratio, the proposed equation is not sensitive to the shear span-to-effective depth as compared to the prediction based on Zhang and Tan's model in figure 7.
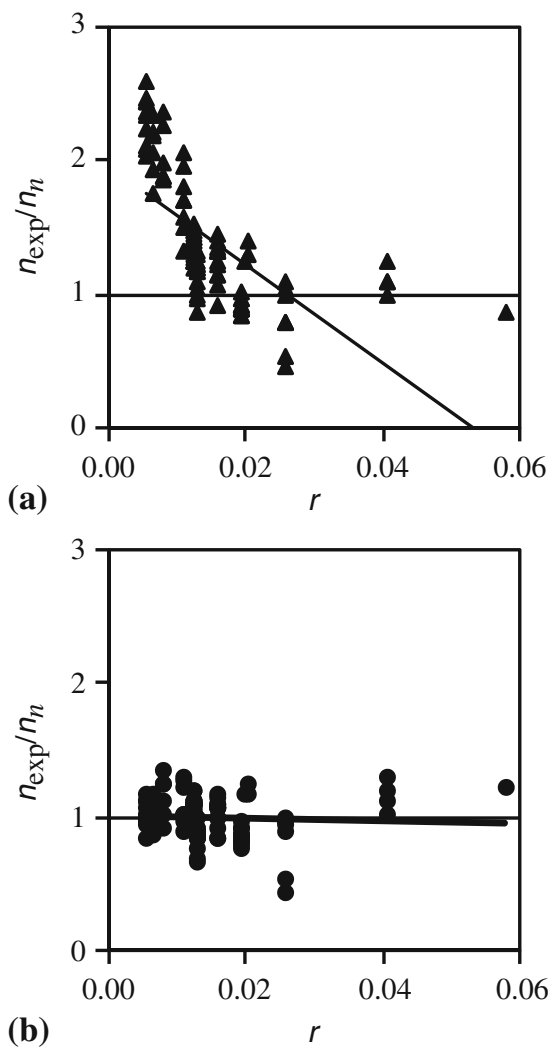

Figure 9. Effect of tensile reinforcement ratio, $\rho$ on shear strength: (a) Zhang and Tan's model; and (b) proposed expression for 96 reinforced concrete deep beams. 


\subsection{Shear stress ratio vs. size of deep beam}

The variation of shear stress ratio with the effective depth of beam is shown in figure 8 . Since the inherent property of softening of concrete after peak is considered by the size effect law in the proposed equation, the prediction is insensitive with increase in depth as compared to Zhang and Tan's model.

\subsection{Shear stress ratio vs. longitudinal main reinforcement ratio}

The appropriate contribution of longitudinal main reinforcement towards the shear strength is reflected in figure 9.

\subsection{Shear stress ratio vs. horizontal web reinforcement ratio}

The role of horizontal web reinforcement is shown in figure 10. The apparent difference between the predictions based on the Zhang and Tan's model and the proposed can be seen from the above figure.
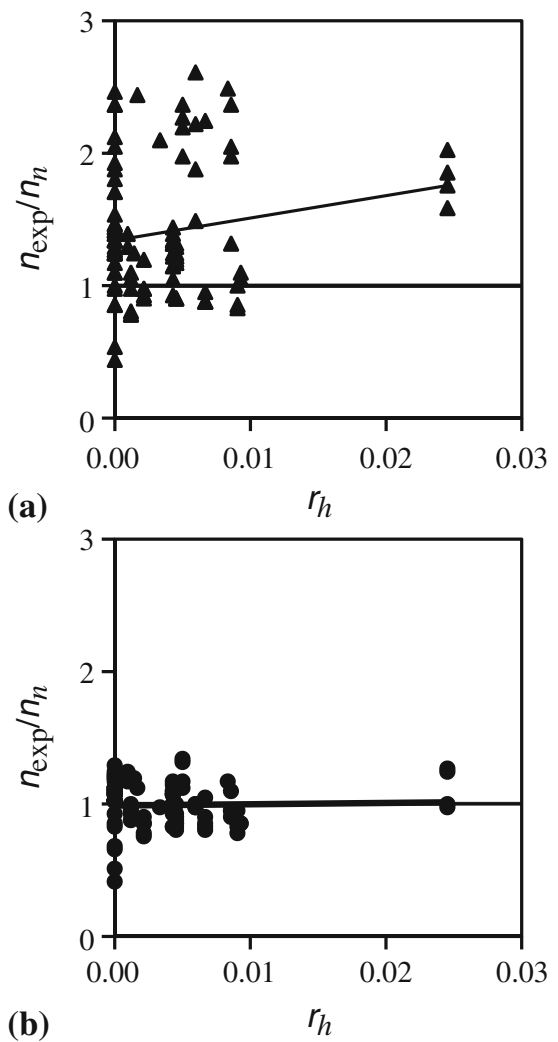

Figure 10. Effect of tensile reinforcement ratio, $\rho_{h}$ on shear strength: (a) Zhang and Tan's model; and (b) proposed expression for 96 reinforced concrete deep beams. 


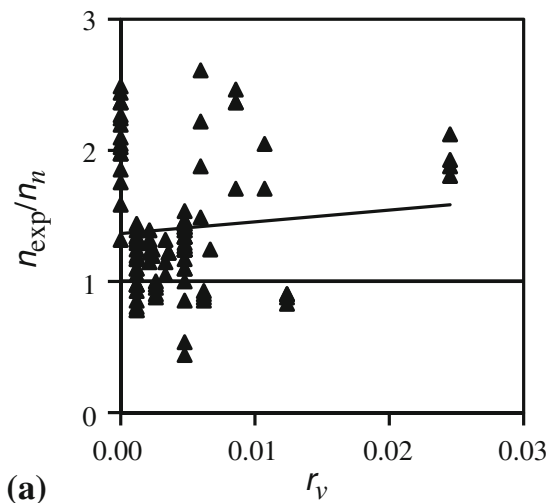

(a)

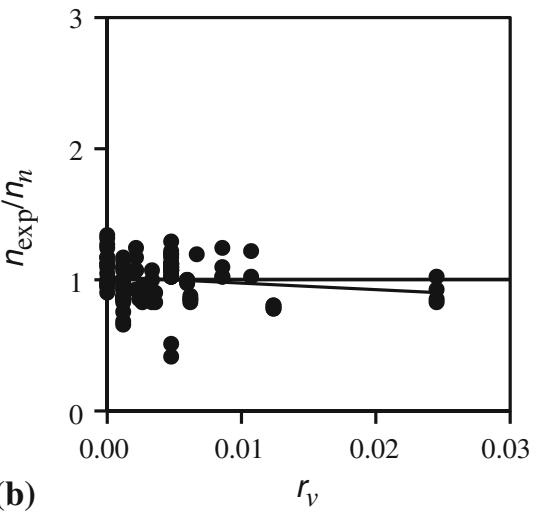

Figure 11. Effect of tensile reinforcement ratio, $\rho_{v}$ on shear strength: (a) Zhang and Tan's model; and (b) proposed expression for 96 reinforced concrete deep beams.

\subsection{Shear stress ratio vs. vertical web reinforcement ratio}

The effect of web reinforcement on the shear strength ratio is shown in figure 11. The aptness of the estimation can be seen from the less displacement of the line representing the mean of the shear stress ratio from the line corresponding to $v_{\text {exp }} / v_{n}=1$.

Hence the proposed model predicts the nominal shear strength of deep beams more uniformly as compared with the existing size effect models.

\section{Conclusions}

The following conclusions can be drawn from the studies on RC deep beams with the analysis of the data base.

(i) It is appropriate to incorporate the size effect in the design of RC deep beams with shear reinforcement for predicting the uniform strength irrespective of the beam size.

(ii) The proposed expression is simple to use as compared to the other existing size effect models, which require laborious iterative procedure. 
(iii) The decrease in nominal stress at failure with the increase in size has been accounted for in the size effect law or in other words, making the stress at failure to depend on size for uniform strength for different range of depths in practice.

(iv) Since the behaviour of short beams $(1<a / d \leq 2.5)$ and slender beams are different from that of deep beams, different equations for these specific cases are required.

\section{Notation}

$\sigma_{N}$ Size-dependent nominal stress at failure in MPa.

$a$ Shear span i.e., distance from the load and nearby reaction

$b$ Breadth of the beam

$d$ Effective depth of beam in $\mathrm{mm}$.

$\lambda_{0}$ A constant

$d_{a}$ Maximum size of coarse aggregate in $\mathrm{mm}$.

$\sigma_{r}$ Size independent nominal stress at failure in MPa.

$k_{1}, k_{2}$, and $k_{4}$ Empirical constants

$f_{t}$ Actual tensile stress in concrete acting across a plane

$V$ Shear force in beam

$v_{n}$ Nominal shear strength of the beam

$V_{\text {exp }}$ Experimentally observed shear force in beam

$v_{\text {exp }}=V_{\text {exp }} /(b d)$ Experimentally observed nominal shear strength of the beam

$f_{c}^{\prime}$ Characteristic cylindrical strength of concrete in MPa.

$n$ Modular ratio of steel to concrete

$E_{s}$ Young's modulus for steel

$E_{c}$ Young's modulus for concrete

$\rho_{h}=A_{s h} /\left(b s_{h}\right)$ Ratios of horizontal web reinforcement

$A_{s h}$ Area of horizontal reinforcement in one level

$s_{h}$ Spacing of horizontal web reinforcement in vertical direction

$\rho_{v}=A_{s v} /\left(b s_{v}\right)$ Ratios of vertical web reinforcement

$A_{s v}$ Area of vertical reinforcement in one position

$s_{v}$ Spacing of vertical web reinforcement in horizontal direction

$\alpha$ Angle between the line joining the points of load and reaction with the horizontal

$z$ Lever arm between centroids of main steel reinforcement and the horizontal compression strut

$j_{0}$ Ratio of lever arm, $z$ to the effective depth, $d$

$k$ Ratio of the depth of neutral axis, $c$ to the effective depth, $d$

$\rho=A_{s} /(b d)$ Main tensile reinforcement ratio

$A_{s}$ Area of main reinforcement

$A_{1}, B_{1}, C_{1}, D_{1}, E_{1}, F_{1}, G_{1}, a_{1}, b_{1}, c_{1}, d_{1}$ Constants.

\section{References}

ACI 3182008 Building code requirements for structural concrete (ACI 318-08) (318R-08) and commentary, American Concrete Institute, Farmington Hills, MI, 465 pp

AASHTO 2007 LRFD Bridge Design Specifications, American Association of State Highway and Transportation Officials, Washington, DC

Bazant Z P 1984 Size effect in blunt fracture: concrete, rock, metal. J. Eng. Mech., ASCE 110(EM4): $518-535$ 
CSA Committee A23.3 1994 Design of Concrete Structures: Structures (Design)—A National Standard of Canada, Canadian Standards Association

de Paiva H A R, Siess C P 1965 Strength and behavior of deep beams in shear. J. Struct. Division, ASCE 91(ST5): 19-41

Kani G N J 1967 How safe are our large reinforced concrete beams? ACI J. Proc. 64(3): 128-141

Kong F K, Robbins P J, Cole D F 1970 Web reinforcement effects on deep beams. ACI J. Proc. 67(12): 1010-1017

Kim J K, Eo S H 1990 Size effect in concrete specimens with dissimilar initial cracks. Mag. Concr. Res. (London) 42(153): 233-238

Kim J K, Park Y D 1996 Prediction of shear strength of reinforced concrete beams without web reinforcement. ACI Mater. J. 93(3): 213-222

Kim D, Kim W, White R N 1999 Arch action in reinforced concrete beams-A rational prediction of shear strength. ACI Struct. J. 96(4): 586-593

Matamoros A B, Wong K H 2003 Design of simply supported deep beams using strut-and-tie models. ACI Struct. J. 100(6): 704-712

Oh J K, Shin S W 2001 Shear strength of reinforced high-strength concrete deep beams. ACI Struct. J. 98(2): 164-173

Russo G, Venir R, Pauletta M 2005 Reinforced concrete deep beams-shear strength model and design formula. ACI Struct. J. 102(3): 429-437

Schlaich J, Schafer K, Jennewein M 1987 Towards a consistent design of structural concrete. PCI J. 32(3): $74-150$

Shioya T, Iguro M, Nojiri Y, Akiayma H, Okada T 1989 Shear strength of large reinforced concrete beams, fracture mechanics: Application to concrete, SP-118. (Detroit: American Concrete Institute) pp. 259-279

Siao W B 1993 Strut-and-tie model for shear behavior in deep beams and pile caps failing in diagonal splitting. ACI Struct. J. 90(4): 356-363

Smith K H, Vantsiotis A S 1982 Shear strength of deep beams. ACI J. Proc. 79(3): 201-213

Tan K H, Cheng G H 2006 Size effect on shear strength of deep beams: investigating with strut-and-tie model. J. Struct. Eng., ASCE 132(5): 673-685

Tan K H, Kong F K, Teng S, Guan L 1995, High-strength concrete deep beams with effective and shear span variations. ACI Struct. J. 92(4): 395-405

Tan K H, Tong K, Teng S 2001 Direct strut-and-tie model for prestressed deep beams. J. Struct. Eng. 127(9): 1076-1084

Tan K H, Tang C Y, Tong K 2003a, A direct method for deep beams with web reinforcement. Mag. Concr. Res. 55(1): 53-63

Tan K H, Tong K, Tang C Y 2003b, Consistent strut-and-tie modeling of deep beams with web openings. Mag. Concr. Res. 55(1): 65-75

Tang C Y, Tan K H 2004 Interactive mechanical model for shear strength of deep beams. ASCE J. Struct. Eng. 130(10): 1534-1544

Walsh P F 1972 Fracture of plain concrete. The Indian Concrete J. 46(11): 469-476

Zhang N, Tan K H 2007 Size effect in RC deeps: Experimental investigation and STM verification. Eng. Struct. 29: 3241-3254 